\title{
A Challenge to the Episodic Account of Negative Compatibility Effect in a Gender Categorization Task: Impact of Prime-Probe Contextual Similarity Versus Time Encoding
}

Sophie Martin, Manuel Jimenez, Nathalie Blanc and Denis Brouillet

\section{(2) OpenEdition}

\section{Journals}

Electronic version

URL: http://journals.openedition.org/cpl/3083

DOI: $10.4000 / \mathrm{cpl} .3083$

ISSN: $1379-6100$

Publisher

Centre PsyCLÉ

Electronic reference

Sophie Martin, Manuel Jimenez, Nathalie Blanc and Denis Brouillet, «A Challenge to the Episodic Account of Negative Compatibility Effect in a Gender Categorization Task: Impact of Prime-Probe Contextual Similarity Versus Time Encoding », Current psychology letters [Online], 23, Vol. 3, 2007। 2007, Online since 18 November 2007, connection on 08 September 2020. URL : http:// journals.openedition.org/cpl/3083; DOI : https://doi.org/10.4000/cpl.3083

This text was automatically generated on 8 September 2020

(c) All rights reserved 


\title{
A Challenge to the Episodic Account of Negative Compatibility Effect in a Gender Categorization Task: Impact of Prime-Probe Contextual Similarity Versus Time Encoding
}

\author{
Sophie Martin, Manuel Jimenez, Nathalie Blanc and Denis Brouillet
}

1 The main objective of this paper was to investigate whether negative priming, occuring as a function of prime/probe response compatibility, is sensitive to contextual overlap between prime and probe displays. Negative priming (NP) experiments usually involve two consecutive displays labelled prime and probe. In each display, participants attend to a target object while ignoring a distracting one. Negative priming refers to the fact that responses to a target on trial $n$ slow down or are less accurate when that target either matches a recently ignored distractor on trial $n-1$ or shares attributes with it. The two broad and competing accounts for the processes underlying negative priming are generally opposed on the temporal direction of their intervention and depend on whether authors focus on attention or on memory processes.

2 According to the inhibitory interpretation, response slowing is attributed to the residual rebound of an active distractor inhibition at the time of prime display (Fox, 1995; Guidi, 2003; May, Kane, \& Hasher, 1995; Neill \& Mathis, 1998; Tipper \& Milliken, 1996) : The probe display indirectly measures the psychological state of the participant during the prime display. The generalization of NP to a wide range of tasks, stimuli and response modes has emphasized the hypothesis of a central and internal locus of inhibition (Fox, 1995; Guidi, 2003; May, Kane, \& Hasher, 1995; Neill \& Mathis, 1998; Tipper \& Milliken, 1996). Tipper, Weaver and Houghton (1994) assumed that only properties of the distractor competing with the subject goals are inhibited, background properties being still available and able to positively influence ongoing behaviour. 
3 The alternative episodic account of negative priming relies on the dynamic proprieties of memory. Neill and Valdes (1992) first proposed that probe automatically cues the retrieval of past processing episodes involving the same information (i.e., in the case of repetition priming). Thus, interference takes place as this information is both associated to a "respond" tag at display $n$ and to a "do not respond" tag at display $n-1$. As episodic retrieval results in a performance impairment, participants have to rely on a long-lasting algorithmic resolution, explaining NP (Neill, 1997; Neill \& Joordens, 2002; Neill, Valdes, \& Terry, 1995; Neill, Valdes, Terry, \& Gorfein, 1992). Other theories involving past instances retrieval have suggested that NP does not result from any kind of selection resolution, but from the detection of a perceptual and conflicting mismatching between the colour of prime and the colour of the target (Park \& Kanwisher, 1994), or by the retrieval of inappropriate processing (Milliken, Tipper, \& Weaver, 1994). In a revisited version of their theory, Neill and Matthis (1998) forwarded the idea that transfer appropriate (TAP) and inappropriate processing (TIP) play an important role in NP. In this view, NP is subsequent to the reinstatement of different processing carried out on a same stimulus at different moments and not to a "do not respond" label. This approach emphasizes the relation between encoding and retrieval processes. Finally, Milliken et al. (1998) proposed another explanation of NP, challenging the distractor-inhibition account, in terms of categorization of stimuli as old or novel. According to the temporal discrimination account, the categorisation of a target that was a recently ignored distractor cannot be done rapidly since the decision new/old leads to ambiguity.

4 A large debate takes place to discern if the demonstration of slowing latencies in the absence of competing distractor during prime display can be considered as a new and strong argument in favour of a memory alternative of NP (Fuentes \& Tudela, 1992; Lowe, 1979; Milliken \& Joordens, 1996; Neill \& Westberry, 1987; Versace \& Allain, 2001; Wood \& Milliken, 1998; Yee, 1991). A number of experiments demonstrated that response compatibility between two isolated stimuli can lead to the occurrence of negative priming effects. Experiments involved nonspatial stimuli such as masked arrows (Eimer \& Schlaghecken, 1998; Schlaghecken \& Eimer, 2002; Schlaghecken \& Maylor, in prep.), colour patches (Fox \& de Fockert, 2001; Law, Pratt, \& Abrams, 1995; Taylor \& Klein, 1995), lines (Francis \& Milliken, 2003) or words (Versace \& Allain, 2001; Yagi \& Kikuchi, 2002) and a variety of tasks such as detection, identification or categorization. This finding is called Negative Compatibility Effect (NCE) to refer to the deletere effect of the prime/target response matching. The question is to know why slower latencies can be observed in the absence of overt selection during prime display if inhibitory processing intervenes in a forward acting manner (Milliken \& Joordens, 1996; Park \& Kanwisher, 1994). The issue is then to investigate whether NP is necessarily attributed to overt selection during prime display, or to the emergence of conflicting properties between prime and target.

Versace and Allain (2001) carried out three experiments to investigate NP. They used a gender categorization task in which there is no distractor, either during prime or probe display. More precisely, participants were informed they would see two successive words, a prime and a target, and were instructed to decide on the target gender only. Prime/target relation could be either valid (i.e., masculine/masculine or feminine/ feminine) or invalid (i.e., masculine/feminine or feminine/masculine). In their first experiment, Versace and Allain (2001) manipulated ISI (i.e., $25 \mathrm{~ms} v S 600 \mathrm{~ms}$ ) while 
maintaining prime duration constant. They predicted slower latencies for valid pairs, compared to invalid ones, only if experimental conditions allowed the detection of conflicting properties between prime and target (i.e., long ISI). Their goal was to demonstrate that slowing latencies can occur without any inhibitory selection. A significant interaction between prime/target relation and ISI was observed with longer latencies for valid pairs $(33 \mathrm{~ms}$ ) in the $600 \mathrm{~ms}$ condition only. However, as participants were explicitly instructed to respond to the target only, their procedure did not permit to control that primes' response were not inhibited when an adequate ISI allowed it. To further investigate this aspect, Versace and Allain (2001) conducted a second experiment. By introducing rows of target letters, they attempted to minimize the prime/target perceptive overlap. Participants were trained to respond "masculine" to the letter "M" and "feminine" to the letter "F". According to the authors, if NP resulted from a forward-acting inhibitory processing, then it should be observed for valid pairs, whatever the type of target presented during probe display (i.e., words or rows of letters). To the reverse, if NP resulted from a backward episodic conflict detected during the target display, then its magnitude should decrease when prime/target overlap is reduced (i.e., in the case of rows of letters). Once again, results fit with a memory based account: NP effects was stable for the valid word/word pairs (33ms) but dramatically reduced for valid word/rows of letters pairs (8ms). The authors concluded by stating that their findings "did not result from an inhibition of the response at the moment of the prime presentation" (Versace \& Allain, 2001, p. 80). In a last and third experiment, Versace and Allain (2001) extended their findings by demonstrating the generalization of NCE to a semantic categorization task based on nature (natural/ artefact). Thus, Negative Compatibility Effect is not task-dependant.

Overall, these findings seem to demonstrate that NP effects may occur without requiring participants to select one over two stimuli as long as a conflict can be detected. According to Versace and Allain (2001), their results univoquely supported a backward-acting memorial processes only. However, as Tipper and Cranston (1985) pointed out, inhibition can be rapidly reduced depending upon the selection demands. More precisely, when participants know the probe display does not require selection, either because single probes are consistently presented or are clearly physically different to probes requiring selection, then they do not maintain a selection state. In that case, response is automatically output to any stimulus present. In such a situation, Tipper and Cranston (1985) hypothesized that inhibition would rapidly decays, revealing activated perceptual representations that would facilitate probe processing. Consequently, the absence of negative validity effect with letters rows in Versace and Allain (2001)'s second experiment can be interpreted as coming from a relinquish of the selection set crucial for inhibitory releasing (Moore, 1994; S. P. Tipper \& M. Cranston, 1985). In that view, we assumed that Versace and Allain (2001)'s results cannot eliminate an inhibitory account of negative compatibility effects.

In order to test an inhibitory interpretation of negative compatibility effects, we based our predictions on the prime/probe contextual similarity principal. Episodic retrieval account has been strongly supported by finding that NP increases when the contextual similarity between prime and probe is high (Fox \& de Fockert, 1998; Kane, May, Hasher, Rahhal, \& Stoltzfus, 1997; Neill, 1997; Wood \& Milliken, 1998). In other words, episodic theory predicts a larger NP when the context of the prime matches the context of the probe (Fox \& de Fockert, 1998; Kane, May, Hasher, Rahhal, \& Stoltzfus, 1997; Neill, 1997; Wong, 2000; Wood \& Milliken, 1998). In their study, Fox et al. (1998) manipulated 
context similarity by varying stimulus intensity of both prime and probe displays. They demonstrated that negative priming is maximal when prime and probe matched in term of contrast (i.e., high/high or low/low), and that the retrospective effect of context similarity overrides the proactive effect of stimuli strength during encoding.

Nevertheless, some studies failed to replicate the impact of contextual similarity on negative priming (Hasher, Zacks, Stoltzfus, Kane, \& Connelly, 1996; Wong, 2000). Kane et al. (1997), who emphasized a dual determination of negative priming, varied the likelihood of episodic retrieval by manipulating exposure duration (i.e., short/long) of both prime and probe stimuli. Prime and target exposure durations conducted to four possible combinations. Episodic theory predicts a larger NP when prime and probe exposure are equivalent (i.e. short/short and long/long). The impact of context similarity should be more determinant than prime's discriminability (i.e., short/short > long/short). Kane et al. (1997) demonstrated that only the short/short condition lead to a marginally significant NP whereas the long/short condition produced the larger effect. Based on these results, we argued that critical determinant processes take place during prime encoding.

The main issue of our study was to investigate further the episodic account of Negative Compatibility Effect in the context of a gender categorization task. In our experiment, we used the same procedure as that one used by Versace and Allain (2001), except that contextual similarity was manipulated by means of information exposition duration. In line of Versace and Allain (2001), we expected our categorisation task to provide evidence for slowing latencies on valid trials compared to invalid ones (NCE) in the absence of any distractive information. We also expected NCE to rise only from properties that consciously participated to the task instructions, that is properties participants focused on as they specified the relevant selection criteria (Tipper, Weaver \& Houghton, 1994). Our main prediction was that NCE would be function of contextual overlap if it relied on episodic retrieval. In other words, following episodic predictions, a larger negative compatibility effects would be observed when prime and probe exposure match than when they mismatch. The context similarity would be more determinant than prime's encoding saliency.

MethodParticipants

Sixty-four students recruited from the University of Montpellier 3, participated as volunteers to this experiment. A1l participants were native French speakers.

Materials

11 We constructed sixty-four pairs of prime/target by using one hundred and twentyeight French words. The material was similar to that one of Versace and Allain (2001). Primes and targets sets did not differ either in word printed frequency, or in number of letters or syllables. Pairs of words did not rhyme and had no evident semantic link. We controlled these dimensions with Lexique3 database (New, Pallier \& Ferrand, 2005). Moreover, a pilot study had be conducted to ensure that primes and targets decision latencies did not differ in a masculine/feminine and natural/artefact categorization task involving single stimuli. For the sixty-four experimental pairs, we manipulated gender and category compatibility, which resulted in four experimental cells that were repeated. Pairs of words could be either 1) valid on both gender and category (e.g. peigne/briquet), 2) valid on gender but invalid on category (e.g. prairie/bague), 3) invalid on gender but valid on category (e.g. muscle/salade) and 4) invalid on both gender and category (e.g. nuage/statue). In other words, concerning gender 
compatibility, half of the pairs matched on their gender (i.e., 32 gender valid pairs: Masculine/masculine or feminine/feminine), the other half was composed of pairs of different gender (i.e., 32 gender invalid pairs masculine/feminine or feminine/ masculine). Concerning category compatibility, half of the experimental pairs consisted of prime and target of the same category (i.e., 32 category valid pairs: Natural/natural or artefact/artefact), and the other half of prime and target of different category (i.e., 32 category invalid pairs: Natural/artefact or artefact/natural). Both category and gender were manipulated within participants. Targets' gender compatibility was counterbalanced within items: same target associated with a compatible prime for one participant was associated with an incompatible prime for another participant.

Procedure

The experiment lasted 20 minutes and was carried out on a TOSHIBA Pentium III pc using the E-prime software (Psychology SoftwareTools, Inc., 2001). The experiment consisted of a practice bloc composed of 32 trials. The experimental bloc that contained 64 experimental trials followed this practice bloc. Stimuli were centered on a black screen, printed in white police Times 20 . As figure 1 illustrated, each trial began with a $1000 \mathrm{~ms}$ fixation cross, followed by a $500 \mathrm{~ms}$ blank screen and primes. Targets were presented after a $1000 \mathrm{~ms}$ ISI.

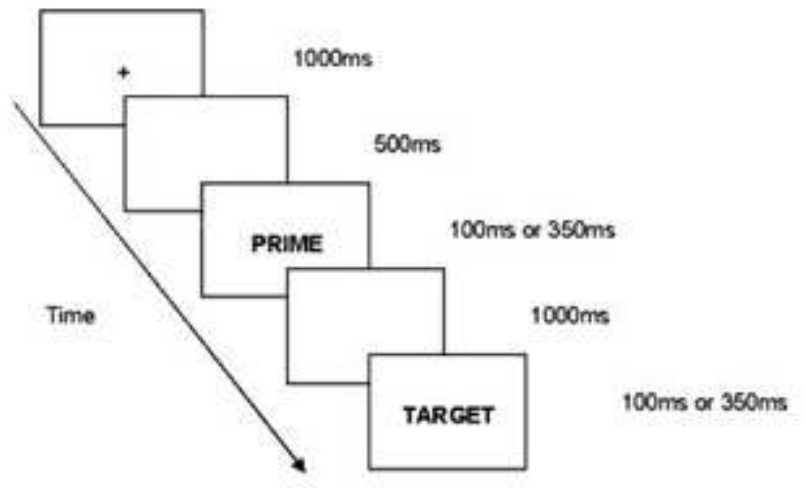

Figure 1. Example of a trial display. Participants had to decide whether targets were

masculine or feminine. They were not conscious of category manipulation.

Prime and target exposure durations were either $100 \mathrm{~ms}$ or $350 \mathrm{~ms}$. We obtained four experimental possible combinations: Brief/brief, brief/long, long/brief and long/long respectively for prime and target exposition. In sum, prime and target exposure manipulations led to two matching conditions (i.e., long/long and brief/brief) and to two mismatching conditions (i.e., brief/long and long/brief).

Participants had to keep their eyes on the fixation cross at the beginning of each trial. They were explicitly instructed not to respond to primes but to read them silently. Their task was to indicate, as quickly and accurately as possible, whether targets were feminine or masculine by pressing one of the two response keys (i.e., $d$ or l). Response keys were counterbalanced between participants. Half of the participants responded masculine with the left hand ( $\mathrm{d}$ key), and the other half with the right hand (l key). They had a maximum of $1200 \mathrm{~ms}$ to respond. The answer on one trial automatically triggered the onset of the next trial. None of the participant was aware of the manipulation of gender and category beween prime and target.

Design 

we conducted a traditional analysis $\left(\mathrm{F}_{1}\right)$ as our experimental design did not require separate analyses over participants and items (Raaijmakers, Schrijnemakers, \& Gremmen, 1999). We submitted latencies to a 2 validity on gender (valid/invalid) x 2 validity on category (valid/invalid) x 2 prime duration (brief/long) x 2 target exposure duration (brief/long) mixed factorial analysis with validity varying within participants and durations between-participants. Response times corresponding to errors and response times below or up to 3 standard deviations were eliminated, which represented less than $5 \%$ of data. Remaining observations were collapsed across participants. Errors are not reported as quite infrequent: Neither main effect nor interaction was revealed.

Predictions

Concerning gender validity, we expected a negative compatibility effect when prime and target matched on their gender (i.e., valid trials). Concerning category validity, we expected positive compatibility effect when pairs matched on their category. Concerning prime and target exposition duration, predictions depended on whether we focus on memory or on attention processes. Following episodic interpretation, NCE should be larger when prime and probe exposure matched than when their mismatched (i.e., long/long and brief/brief). Following inhibitory interpretation, we expected a larger NCE when primes exposition was longer (i.e., long/brief and long/ long conditions). In other words, prime's encoding saliency should be more determinant than context similarity.

Results

We conducted an analysis of variance on the participants' response times to the gender categorisation task. Participants were used as the random variable. We obtained two main effects. As presented in Table 1, there was a main effect of gender validity with slower latencies on valid trials $(\mathrm{M}=634.91 \mathrm{~ms})$ relative to invalid ones $(\mathrm{M}=622.82 \mathrm{~ms})$, that is a $12.09 \mathrm{~ms}$ negative compatibility effect, $F(1,60)=11.21, p<.05$. In other word, responses were faster when prime and target had different gender. There was also a significant effect of category validity, $\mathrm{F}(1,60)=10.35, \mathrm{p}<.01$ : Participants were speeded up by prime/target category matching (positive compatibility effect of 9,89 ms). Thereby, background properties of information that do not participate to selection, such as category, are still available and positively influence behaviour. Responses were faster when prime and target shared the same category. Prime duration manipulations had no effect on general reaction times $(\mathrm{F}<1)$, while shortening target exposure duration slowed overall responses, $F(1,60)=4.54, p<.01$. No other factor nor interaction was significant. 
Table I

Mean response times (in ms) and compatibility effects for the Gender and Category ( ${ }^{*} p<05$

and ** $p<01$ ) as a function of all prime/target exposition conditions

\begin{tabular}{|c|c|c|c|c|c|c|c|c|c|}
\hline \multirow[b]{4}{*}{ Trion Type } & \multirow[b]{4}{*}{ Overall } & \multicolumn{8}{|c|}{ Ptmotarget exposure durations } \\
\hline & & \multicolumn{2}{|c|}{ Eneotrief. } & \multirow{2}{*}{\multicolumn{2}{|c|}{$\frac{\text { Bnedrong }}{\text { RT }}$}} & \multirow{2}{*}{\multicolumn{2}{|c|}{$\frac{\text { Longeried }}{\text { हRT }}$}} & \multirow{2}{*}{\multicolumn{2}{|c|}{$\frac{\text { Longliong }}{\text { DTt }}$}} \\
\hline & & \multicolumn{2}{|c|}{ RT } & & & & & & \\
\hline & & M & $S O$ & M & \multirow[t]{2}{*}{ SO } & \multirow[t]{2}{*}{$M$} & \multirow[t]{2}{*}{ so } & \multirow[t]{2}{*}{ M } & \multirow[t]{2}{*}{ SO } \\
\hline Gender & & & & & & & & & \\
\hline Vallo & 634.92 & 664.40 & 72.27 & 524.02 & 78,50 & 647,55 & 85.27 & 633.71 & 9106 \\
\hline Imvald & 622,62 & 655,15 & 66,16 & 591,50 & 77,86 & 630,44 & 70,36 & 694,13 & 8180 \\
\hline Yals-inviald & $120 \%$ & 9.25 & & 2.46 & & $17,10^{\circ}$ & & $19.55^{*}$ & \\
\hline \multicolumn{10}{|l|}{ Catepary } \\
\hline Vald. & 623,82 & 660.32 & 73,76 & 591,02 & 76,69 & 630.50 & 72.27 & 613,85 & 85,85 \\
\hline Itrvald & 603.82 & 659,23 & 61,72 & 594,56 & 70,54 & 647,49 & 89,64 & 63390 & 87,80 \\
\hline vassilinated & $.9,0 g^{\prime \prime}$ & 1.00 & & .3 .54 & & $-18,96$ & & $-20,13^{H}$ & \\
\hline
\end{tabular}

To test our predictions concerning context similarity, we conducted planned comparisons by carrying out, in each of the four prime/target exposition condition, a repeated analyses of variance with gender validity (valid vs invalid) and category validity (valid vs invalid) as within-subject variables. We also conducted a Wilcoxon Rank Test in order to investigate the reliability of our results over participants.

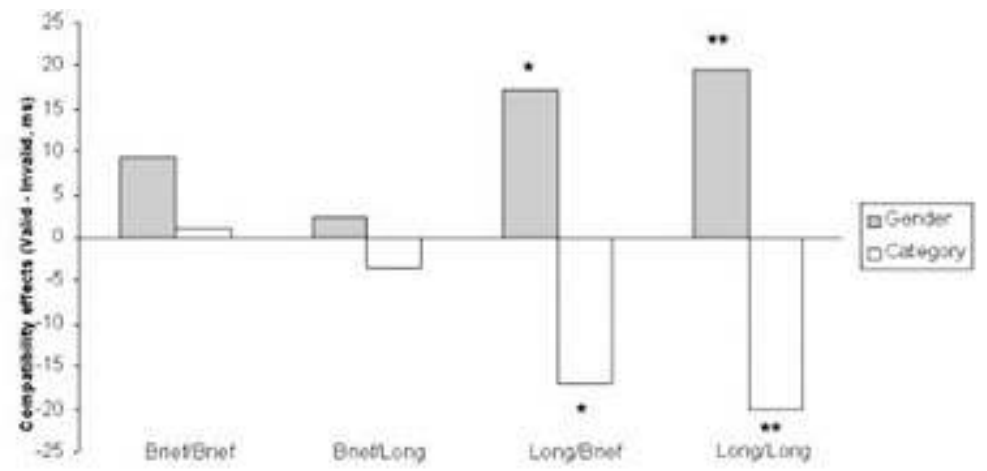

Figure 2, Compatibility Effect (ms) for Gender and Category (the difference between valid

and invalid trials) as a function of prime target exposure duration $\left(* p<.05\right.$ and $\left.{ }^{* *} p<.01\right)$

As illustrated in figure 2, the analysis of variance revealed that we did not obtain a validity effect of gender and category in the brief/brief condition, nor in the brief/long condition. This effect appeared in the long/brief , $F(1,60)=8.28, p<.05$ for gender and $F(1,60)=7.2, p<.05$ for category, and in the long/long, $F(1,60)=11.19, p<.01$ for gender and $F(1,60)=10.18, p<.01$ for category, conditions (see figure 2).

The absence of validity effect in the first two conditions was consistent as in the brief/ long condition, only $43,7 \%$ of the participants exhibited validity effect for gender ( $\mathrm{z}=$ 0.103 , NS, Wilcoxon rank) and only $56,25 \%$ of the participants for category $(\mathrm{z}=0.827$, NS, Wilcoxon rank). In the same line, in the brief/brief condition, only $56,25 \%$ of the participants exhibited a gender validity effect $(z=0.982$, NS, Wilcoxon rank) and $37,5 \%$ of the participants a category validity effect $(\mathrm{z}=0.103$, NS, Wilcoxon rank). Oppositely, response latencies were longer when prime and target matched on gender than when they mismatched for $81.25 \%$ of participants in the long/brief condition $(\mathrm{z}=2.585, p<$. 
01 , Wilcoxon rank) and $87.5 \%$ of the participants in the long/long condition $(\mathrm{z}=2.53$, $p<.01$, Wilcoxon rank). Concerning category, $81.25 \%$ of the participants of in the long/ brief condition $(\mathrm{z}=3.05, \mathrm{p}<.003$, Wilcoxon rank) and $62.5 \%$ of the participants in the long/long condition ( $\mathrm{z}=1.758, p=.07$, Wilcoxon rank) presented faster response times when prime and target matched on their category.

Discussion

In this study, we focused on negative compatibility effect (NCE) which refers to the fact that prime/target response matching gives rise to behavioural cost. Two opposite explanations are usually provided to explain this effect. According to the episodic account, NCE results from a backward-acting processing from target to prime. The logic of episodic retrieval is that NCE should increase as the contextual overlap between prime and target increases (Kane, May, Hasher, Rahhal, \& Stoltzfus, 1997; Neill, 1991, , 1997; Wong, 2000). To the opposite, the inhibitory account emphasizes that NCE results from a forward-acting processing from prime to target and depends on the prime encoding saliency.

In line with the study of Versace and Allain (2001), we explored NCE using a priming paradigm in which prime and probe displays contained isolated information without any distractor. We manipulated prime/probe compatibility on gender. Participants had to decide whether targets were masculine or feminine. They were explicitly informed not to respond to primes. Our primary goal was to examine whether negative compatibility effect was higher when episodic retrieval of primes was emphasized. Thus, we investigated whether NCE varies as a function of prime/target contextual similarity by manipulating both prime/target response matching on their gender and their category, and prime/target contextual similarity through their exposure duration. To go further than Versace and Allain (2001)'s study, we also manipulated prime/probe compatibility on category in order to examine whether NCE concerned only properties that consciously participated to task instructions (i.e., the gender).

Our findings did not fit with an episodic unified account of negative compatibility effect as suggested by Versace and Allain (2001). According to these authors, primes presented before targets gave rise to behavioural costs when pairs were mapped to the same response compare to pairs that were mapped to opposite ones. However, NCE only concerned the proceeded stimulus dimension specifying the task critical selection criteria (i.e., gender). In addition and as predicted by Tipper, Weaver and Houghton (1994), we observed that prime/target response matching, on other dimensions that the one specifying the selection criteria, gave rise to behavioural benefits (i.e., category) and not to costs. Moreover, we also demonstrated that the magnitude of NCE is independent from prime and target contextual overlap. The critical factor that favours NCE was the time spent in primes encoding but not the contextual similarity between primes and targets. NCE occurred for long primes, whatever probe durations and prime/probe contextual similarity (i.e., long/brief and long/long duration). These data nicely fit with Kane et al. (1997)'s results. They demonstrated that temporal overlap only leads to a marginal negative priming when primes are briefly encoded (see also Wong, 2000). The inhibitory account of negative priming posits that the level of inhibition of a distractor, by nature reactive, depends on its own activation state. As a result, negative priming, and therefore negative compatibility effect, might not be developed in the presence of low distractive information, as it was the case in the 
short/long and short/short conditions (Houghton \& Tipper, 1994; Lowe, 1979; Moore, 1994; Tipper \& M. Cranston, 1985; S. P. Tipper \& M. Cranston, 1985).

One can argue that both attentional and memorial theories can explain that longer exposition of primes is a necessary condition for NCE to occur. According to episodic account, the probability of memorial retrieving depends both on the strength and the accessibility of previous episodes which are largely reduced when little time is allowed for primes encoding. Therefore, the lack of effect of prime/probe similarity could be due to our procedure that does not enhance significantly the likelihood of episodic retrieval. Nevertheless, as noticed by Wong (2000), such an argument is quite unfalsifiable. Indeed, he argued that "any experiment showing an absence of primeprobe similarity effect would be attributed to the manipulation of prime-probe similarity not being strong enough, which is inferred from NP not being dependant on prime-probe similarity" (Wong, 2000, p 1412). Therefore, if our results do not provide a direct evidence for an inhibitory account of NCE, we assume that they directly map NCE to encoding processes. In other words, our work seriously challenges Versace and Allain' (2001) episodic interpretation of negative compatibility effects as a unified theory. It gives another line of evidence that negative compatibility effect is at least dually determined by both encoding and retrieval processes. Indeed, our results clearly demonstrate that an experimental design that should induce episodic retrieval (such as prime-probe contextual similarity) is not sufficient as long as time allowed to prime encoding is not long enough. Obviously, both attention and memory processing play an inextricably tied role behaviour determination (Kane, May, Hasher, Rahhal, \& Stoltzfus, 1997; May, Kane, \& Hasher, 1995; Neill, Valdes, \& Terry, 1995; Tipper, 2001).

Further researches are needed to investigate to which extend Negative Compatibility Effect, such as negative priming, assesses the contribution of both inhibition and episodic retrieval within the same task. Following that perspective, we are actually conducting new experiments using repetition priming and degraded items. Those contextual manipulations are intended to increase the probability of inducing episodic retrieval (Kane, May, Hasher, Rahhal, \& Stoltzfus, 1997; Martin, 2004). In this way, we expect to observe larger NCE for repeated items and degraded-target trials compared to standard trial. To conclude, and as suggested in a previous work (Martin, Brouillet, Guerdoux, \& Tarrago, 2006), NCE is an new interesting way to investigate dual determination of performance in studies dealing with population such as older people (Brouillet \& Martin, 2005).

\section{BIBLIOGRAPHY}

Brouillet, D., \& Martin, S. (2005). La psychologie cognitive à l'écoute du vieillissement. In J.-M. Talepin (Ed.), Cinq paradigmes du vieillissement. Paris: Dunod.

Eimer, M., \& Schlaghecken, F. (1998). Effects of masked stimuli on motor activation: Behavioral and electrophysiological evidence. Journal of Experimental Psychology. Human

Perception and Performance, 24(6), 1737-1747. 
Fox, E. (1995). Negative priming from ignored distractors in visual selection: A review.

Psychonomic Bulletin and Review, 2, 145-173.

Fox, E., \& de Fockert, J. W. (1998). Negative priming depends on prime-probe similarity : Evidence for episodic retrieval. Psychonomic Bulletin and Review, 5, 107-113.

Fox, E., \& de Fockert, J. W. (2001). Inhibitory effects of repeating a color and shape: Inhibition of return or repetition blindness? Journal of Experimental Psychology. Human

Perception and Performance, 27, 798-812.

Francis, L., \& Milliken, B. (2003). Inhibition of return for the length of a line? Perception \& Psychophysics, 65(8), 1208-1221.

Fuentes, L. J., \& Tudela, P. (1992). Semantic processing of foveally and parafoveally presented words in a lexical decision task. Quarterly Journal of Experimental Psychology: Human Experimental Psychology, 45, 299-322.

Guidi, A. (2003). Inhibition et vieillissement : L'amorçage négatif dans une tâche d'identification ou de localisation. Unpublished Experimental and Cognitive Psychology Thesis, Université Paul Valery.

Hasher, L., Zacks, R. T., Stoltzfus, E. R., Kane, M. J., \& Connelly, S. L. (1996). On the time-course of negative priming : Another look. Psychonomic Bulletin \& Review, 3(231-237).

Houghton, G., \& Tipper, S. P. (1994). A model of inhibitory mechanisms in selective attention. In D. Dagenbach \& T. H. Carr (Eds.), Inhibitory processes in attention, memory, and language (pp. 53-112). San Diego, CA: Academic Press.

Kane, M. J., May, C. P., Hasher, L., Rahhal, T. A., \& Stoltzfus, E. R. (1997). Dual mechanisms of negative priming. Journal of Experimental Psychology: Human Perception and Performance, 23, 632-650.

Law, M. B., Pratt, J., \& Abrams, R. A. (1995). Color-based inhibition of return. Perception \& Psychophysics, 57(402-408).

Lowe, D. G. (1979). Strategy, context, and the mechanism of reponse inhibition. Memory and Cognition, 7, 382-389.

Martin, S. (2004). De l'inhibition contrôlée au contrôle de l'inhibition : une approche fonctionnelle du déficit lors du vieillissement. Unpublished Experimental and Cognitive Psychology Thesis, Paul Valéry, Montpellier.

Martin, S., Brouillet, D., Guerdoux, E., \& Tarrago, R. (2006). Inhibition et capacité de contrôle lors $\mathrm{du}$ vieillissement normal : confrontation de l'hypothèse dorso-ventrale et de l'hypothèse frontale dans l'effet d'amorçage négatif. L'Encéphale, 32(1), 253-262.

May, C. P., Kane, M. J., \& Hasher, L. (1995). Determinants of negative priming. Psychological Bulletin, 118, 35-54.

Milliken, B., \& Joordens, J. (1996). Negative priming without overt prime selection. Canadian Journal of Experimental Psychology, 50(4), 333-346.

Milliken, B., Joordens, S., Merikle, P. A., \& Seiffert, A. E. (1998). Selective attention: a reevaluation of the implications of negative priming. Psychological Review, 105, 203-229.

Milliken, B., Tipper, S. P., \& Weaver, B. (1994). Negative priming in a spatial localization task: Feature mismatching and distractor inhibition. Journal of Experimental Psychology: Human Perception and Performance, 20, 624-646. 
Moore, C. M. (1994). Negative priming depends on probe-trial conflict: Where has all the inhibition gone? Perception \& Psychophysics, 56, 133-147.

Neill, W. T. (1991). Consciousness and the inhibitory control of cognition. Paper presented at the 99th Anual Convention of the American Psychological Association, San Francisco.

Neill, W. T. (1997). Episodic retrieval in negative priming and repetition priming. Journal of Experimental Psychology: Learning, Memory, \& Cognition, 23, 1291-1305.

Neill, W. T., \& Joordens, S. (2002). Negative priming and multiple repetition: A reply to Grison and Strayer (2001). Perception \& Psychophysics, 64(5), 855-860.

Neill, W. T., \& Mathis, K. M. (1998). Transfert-inappropriate processing: Negative priming and related phenomena. In D. L. Medin (Ed.), The psychology of learning and motivation : Advances in research and theory (Vol. 38, pp. 1-44). San Diego: Academic Press.

Neill, W. T., \& Valdes, L. A. (1992). Persistence of negative priming: Steady-state or decay? Journal of Experimental Psychology: Learning, Memory, and Cognition, 18, 565-576.

Neill, W. T., Valdes, L. A., \& Terry, K. M. (1995). Selective attention and the inhibitory control of cognition. In F. N. Dempster \& C. J. Brainerd (Eds.), Interference and inhibition in cognition (pp. 207-261). New York: Academic Press.

Neill, W. T., Valdes, L. A., Terry, K. M., \& Gorfein, D. S. (1992). The persistence of negative priming: II. Evidence for episodic trace retrieval.Journal of Experimental Psychology: Learning, Memory, \& Cognition, 18, 993-1000.

Neill, W. T., \& Westberry, R. L. (1987). Selective attention and the suppression of cognitive noise. Journal of Experimental Psychology: Learning, Memory and Cognition, 13, 327-334.

Park, J., \& Kanwisher, N. (1994). Negative priming for spatial locations: identity mismatching, not distractor inhibition. Journal of Experimental Psychology: Human Perception and Performance, 20(3), 613-623.

Raaijmakers, J. G. X., Schrijnemakers, J. M. C., \& Gremmen, F. (1999). How to deal with "the language-as-fixed-effect fallacy": common misconceptions and alternative solutions. Journal of Memory and Language, 41, 416-426.

Schlaghecken, F., \& Eimer, M. (2002). Motor activation with and without inhibition: Evidence for a threshold mechanism in motor control. Perception \& Psychophysics, 64, 148-162.

Schlaghecken, F., \& Maylor, E. A. (in prep.). Motor Control in old age: Evidence of Impaired lowlevel inhibition. Cortex.

Taylor, T. L., \& Klein, R. M. (1995). Inhibition of return to color: a replication and nonextension of Law, Pratt and Abrams. Perception \& Psychophysics, 60, 1452-1456.

Tipper, \& Cranston, M. (1985). Selective attention and priming: Inhibitory and facilitory effects of ignored primes. Quarterly Journal of Experimental Psychology, 37A, 591-611.

Tipper, S. P. (2001). Does negative priming reflect inhibitory mechanism? A review and integration of conflicting views. The Quarterly Journal of Experimental Psychology, 54A(2), 321-343.

Tipper, S. P., \& Cranston, M. (1985). Selective attention and priming: Inhibitory and facilitory effects of ignored primes. Quarterly Journal of Experimental Psychology, 37A, 591-611. 
Tipper, S. P., \& Milliken, B. (1996). Distinguishing between inhibition and episodic retrieval based accounts of negative priming. In A. Kramer, M. Coles \& G. D. Logan (Eds.), Proceedings of the conference on converging operations in visual selective attention (pp. 337-364). Waschington DC: American Psychological Association.

Tipper, S. P., Weaver, B., \& Houghton, G. (1994). Behavioural goals determine inhibitory mechanisms of selective attention. Quarterly Journal of Experimental Psychology, 47A, 809-840.

Versace, R., \& Allain, G. (2001). Negative priming in a gender decision task and in a semantic categorization task. Acta Psychologica, 108, 73-90.

Wong, K. F. E. (2000). Dissociative prime-probe contextual effects on negative priming and repetition priming: A challenge to episodic retrieval as a unified account of negative priming. Journal of Experimental Psychology: Learning, Memory, and Cognition, 26, 1411-1422.

Wood, T. J., \& Milliken, B. (1998). Negative priming without ignoring. Psychonomic Bulletin \& Review, 5(470-475).

Yagi, Y., \& Kikuchi, T. (2002). Negative compatibility effect at post-categorical level. Paper presented at the Attention and Cognition 2nd Workshop, Tokyo.

Yee, P. L. (1991). Semantic inhibition of ignored words during a figure classification task. Quarterly Journal of Experimental Psychology, 43A, 127-153.

\section{ABSTRACTS}

Negative Compatibility Effect (NCE) refers to the fact that a negative priming effect appears when prime/target pairs are mapped to the same response compared to pairs that are mapped to the opposite one. In a gender categorisation task, Versace and Allain (2001) explained this result by a backward-acting memorial processes leading to the detection of a conflict between prime and target responses. In this paper, we investigated whether NCE is stronger in condition enhancing episodic retrieval (Fox \& de Fockert, 1998; Kane et al., 1997; Wong, 2000). We manipulated the contextual similarity between prime and target through information exposition duration. Our results do not emphasize episodic retrieval as a unified account for NCE: The critical determinant of NCE was the time allowed for primes encoding but not the contextual overlap between prime and target.

L'Effet de Compatibilité Négative (ECN) renvoie au fait que la compatibilité des réponses entre amorçe et cible donne lieu à un ralentissement des temps de décision comparativement à une condition d'incompatibilité. Dans une tâche de catégorisation sur le genre, Versace et Allain (2001) expliquent cet effet d'amorçage négatif par la réévocation épisodique de traces mnésiques entrant en conflit. Afin de mettre à l'épreuve cette hypothèse, nous évaluons si l'intensité de l'Effet de Compatibilité Négative augmente dans des conditions expérimentales favorisant la récupération épisodique mnésique (Fox \& de Fockert, 1998; Kane et al., 1997; Wong, 2000). Dans ce but, nous manipulons la similarité contextuelle entre amorce et cible par le biais des temps d'exposition. Nos résultats montrent qu'une interprétation épisodique ne peut rendre compte de façon unifiée de l'ECN. Le facteur déterminant de l'ECN se révèle être le temps alloué à l'encodage des informations plus que la similarité des traitements entre amorces et cibles. 
INDEX

Keywords: Categorization, Negative Compatibility Effect, Inhibition, Episodic Retrieval, Contextual Similarity

\section{AUTHORS}

\section{SOPHIE MARTIN}

Laboratoire Lameco, University of Montpellier 3, Route de Mende, 34199 Montpellier Cedex 5 France. sophiesmr@aol.com

MANUEL JIMENEZ

University of Montpellier 3, France

NATHALIE BLANC

University of Montpellier 3, France

DENIS BROUILLET

University of Montpellier 3, France 